\title{
The impact of frailty on functional survival in patients 1 year after cardiac surgery
}

\author{
James Lytwyn, BSc, ${ }^{a}$ Andrew N. Stammers, BKin, ${ }^{\mathrm{a}, \mathrm{b}}$ D. Scott Kehler, MSc, ${ }^{\mathrm{a}, \mathrm{b}}$ Patrick Jung, MD, \\ Bryce Alexander, BSc, ${ }^{a}$ Brett M. Hiebert, MSc, ${ }^{a}$ Chris Dubiel, BSc, ${ }^{a}$ Dustin Kimber, BKin, ${ }^{2}$

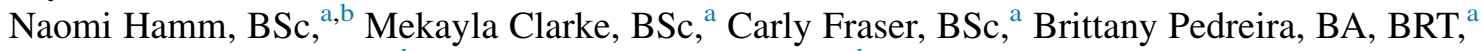 \\ Todd A. Duhamel, PhD, ${ }^{\mathrm{a}, \mathrm{b}}$ Navdeep Tangri, MD, PhD, ${ }^{\mathrm{d}}$ and Rakesh C. Arora, MD, PhD ${ }^{\mathrm{a}, \mathrm{c}}$
}

\section{ABSTRACT}

Objective: This study determined whether frailty provides incremental value to the European System for Cardiac Operative Risk Evaluation II in identifying patients at risk of poor 1-year functional survival.

Methods: This prospective study in patients undergoing cardiac surgery defined frailty using 3 common definitions: (1) the Modified Fried Criteria; (2) the Short Physical Performance Battery; and (3) the Clinical Frailty Scale. The primary outcome was functional survival, defined as being alive at 1 year postsurgery with a health-related quality of life score greater than 60 on the EuroQol-Visual Analogue Scale.

Results: Of the 188 participants, $49.5 \%, 52.6 \%$, and $31.9 \%$ were deemed frail according to the Modified Fried Criteria, Short Physical Performance Battery, and Clinical Frailty Scale, respectively. The median age of our cohort was 71.0 years $(29.3 \%$ female). The probability of functional survival at 1 year for the entire cohort was $73.9 \%$. After adjusting for the European System for Cardiac Operative Risk Evaluation II, patients deemed frail under the Modified Fried Criteria, Short Physical Performance Battery, and Clinical Frailty Scale had an increased odds ratio for poor functional survival of 3.44, 3.47, and 2.08, respectively. When compared with the European System for Cardiac Operative Risk Evaluation II alone, the Modified Fried Criteria, Short Physical Performance Battery, and Clinical Frailty Scale showed an absolute improvement in the discrimination slope of $6.7 \%, 6.5 \%$, and $2.4 \%$ with a category-free classification improvement of $59.6 \%, 59.2 \%$, and $35.1 \%$, respectively.

Conclusions: Preoperative frailty was associated with a 2- to 3.5-fold higher risk of poor functional survival 1 year after cardiac surgery. The addition of frailty to the European System for Cardiac Operative Risk Evaluation II provides incremental value in identifying patients at risk of poor functional survival 1 year postsurgery, regardless of frailty definition. (J Thorac Cardiovasc Surg 2017;154:1990-9)

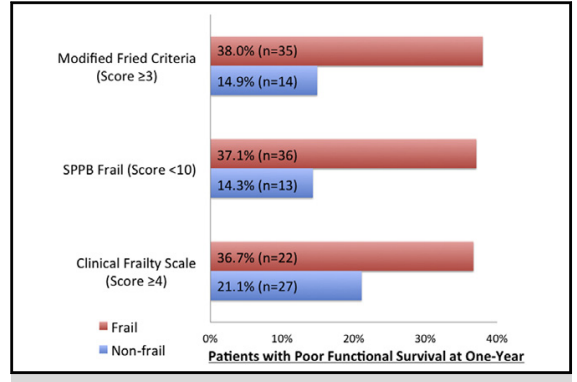

Frail patients are at a higher risk of poor functional survival after cardiac surgery.

\section{Central Message}

Adding frailty to the euroSCORE II provides incremental value in identifying patients at risk of poor functional survival 1 year after cardiac surgery.

\section{Perspective}

Functional survival, defined as being alive 1 year after cardiac surgery and having an adequate HRQoL, is a relevant patientcentered outcome. Identifying patients undergoing cardiac surgery at risk of poor functional survival would allow clinicians to improve the quality of patients' informed consent and allow healthcare teams to target modifiable risk factors perioperatively.

See Editorial Commentary page 2000.

See Editorial page 1988.
As the global population ages, increasingly older and frail patients are presenting for cardiac surgery worldwide. ${ }^{1}$ Recent analyses in this aging demographic of patients

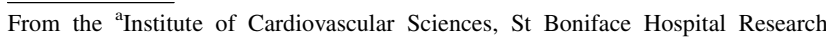

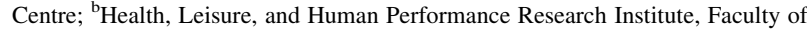
Kinesiology and Recreation Management, ${ }^{\mathrm{c}}$ Department of Surgery, Faculty of Health Sciences, and ${ }^{\mathrm{d}}$ Seven Oaks Hospital, University of Manitoba, Winnipeg, Manitoba, Canada.

Funded by a Department of Surgery Grant, University of Manitoba, Winnipeg, Manitoba, and the Dr James Pullar Memorial Trust. A.N.S. was supported by a CIHR Canada Graduate Scholarship and the University of Manitoba Jack MacDonell Scholarship for Research in Aging. have identified that in addition to survival, maintaining or improving health-related quality of life (HRQoL) after their surgical procedure is of equal if not greater importance. ${ }^{2,3}$ It

\footnotetext{
N.T. and R.C.A. contributed as co-senior authors of this article.

Received for publication Oct 9, 2016; revisions received June 1, 2017; accepted for publication June 17, 2017; available ahead of print July 19, 2017.

Address for reprints: Rakesh C. Arora, MD, PhD, I. H. Asper Clinical Research, St Boniface Hospital, CR3012-369 Tache Ave, Winnipeg, Manitoba R2H 2A6, Canada (E-mail: rakeshcarora@gmail.com). $0022-5223 / \$ 36.00$ Copyright (c) 2017 by The American Association for Thoracic Surgery http://dx.doi.org/10.1016/j.jtcvs.2017.06.040
} 


\section{Abbreviations and Acronyms \\ AUC = area under the curve \\ CFS $\quad=$ Clinical Frailty Scale \\ EQ-VAS = EuroQol-Visual Analogue Scale \\ euroSCORE $=$ European System for Cardiac \\ Operative Risk Evaluation \\ HRQoL = health-related quality of life \\ IDI $=$ Integrated Improvement Index \\ MFC $\quad=$ Modified Fried Criteria \\ NRI $\quad=$ Net Reclassification Index \\ SPPB $\quad=$ Short Physical Performance Battery}

Scanning this QR code will take you to the article title page.

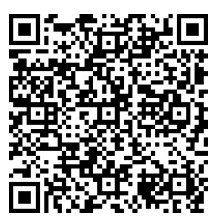

has been estimated that up to one half of older adults currently undergoing cardiac surgery can be considered frail. ${ }^{4,5}$ These patients are vulnerable to both in-hospital adverse outcomes and poor long-term HRQoL. ${ }^{6}$

Frailty can be defined as a biological syndrome of decreased physiologic reserve and resistance to stressors, resulting in increased vulnerability to adverse outcomes. ${ }^{6}$ Frail individuals have a significantly higher risk of falls, disability, hospitalizations, and death, particularly after major medical or surgical events. ${ }^{6-8}$ It is well established that cardiac surgery represents a major physiologic stressor, and patients who are frail are at an increased risk of major cardiac or cerebrovascular events, postoperative delirium, increased hospital length of stay, morbidity, and mortality. ${ }^{4,5,8-11}$

The 2 most commonly used preoperative risk assessment tools in cardiac surgery, the Society of Thoracic Surgeons Predicted Risk of Mortality and Morbidity and the European System for Cardiac Operative Risk Evaluation (euroSCORE) II, do not include comprehensive measures of frailty. Furthermore, although these scores have been shown to provide adequate prediction of perioperative mortality and morbidity, ${ }^{12,13}$ there is a paucity of literature examining their ability to predict long-term "functional survival," defined as being alive with a good HRQoL. ${ }^{14}$ Accurate prediction of functional survival can help guide treatment decisions for the patient, aid in informed consent, and improve patient selection for cardiac surgery. ${ }^{15}$

We conducted a prospective cohort study to determine the relative ability of 3 commonly used frailty measures to predict 1-year functional survival: (1) the Modified Fried Criteria (MFC), ${ }^{6}$ (2) the Short Physical Performance Battery (SPPB), ${ }^{16}$ and (3) the Clinical Frailty Scale (CFS). ${ }^{17} \mathrm{We}$ hypothesized that these preoperative measures of frailty, when added to current risk-assessment scores, would provide incremental value in identifying patients at risk of poor 1-year outcomes in patients undergoing cardiac surgery.

\section{MATERIALS AND METHODS Study Population}

The study was conducted at the St Boniface Hospital, a tertiary care center in Winnipeg, Canada, with a patient catchment of approximately 1.1 million people. The study was approved by the University of Manitoba Research Ethics Board and the St Boniface Hospital Research Review Committee before the initiation of the study. Patients aged more than 18 years and undergoing elective or urgent coronary artery bypass graft or valve procedures were eligible for enrollment in the study. Patients who gave informed consent within this investigation were initially enrolled as part of a previous study protocol. ${ }^{4}$ From this cohort, patients were subsequently approached for follow-up between 9 and 19 months after their index (ie, initial) operative procedure. Because of the nature of the initial study examining the impact of frailty on postoperative delirium, ${ }^{4}$ patients in whom postoperative delirium could not be reliably assessed were excluded (eg, patients with previous stroke, cerebral palsy, severe dementia, severe hearing disabilities, or the inability to understand English).

\section{Measurements and Outcomes}

Frailty assessment. The primary exposure variable was frailty, defined using 3 common definitions. Study participants underwent detailed frailty assessments, namely, (1) the MFC, ${ }^{6}$ (2) the SPPB, ${ }^{16}$ and (3) the $\mathrm{CFS} .{ }^{17}$ Under the Modified Fried definition, a patient was deemed "frail" if he/she met 3 or more of the following 7 criteria: slowness (as determined by the $5-\mathrm{m}$ gait speed measurement, average time on 2 trials $>6$ seconds), weakness (a handgrip strength measurement, $\leq 30 \mathrm{~kg}$ if male, $\leq 20 \mathrm{~kg}$ if female), ${ }^{6}$ weight loss (self-reported weight loss $>4.5 \mathrm{~kg}$ or $>5 \%$ body weight in past 12 months), ${ }^{6}$ exhaustion (the modified 2-item Center for Epidemiologic Studies Depression Scale; $\geq 1$ of 2 ) ${ }^{18}$ depression (the 5 -item Geriatric Depression Scale; $\geq 2$ of 5 ), ${ }^{19,20}$ low physical activity (the Paffenbarger Physical Activity Index; $<383 \mathrm{kcal}$ per week if male, $<270 \mathrm{kcal}$ per week if female), ${ }^{21}$ and cognitive impairment (the Montreal Cognitive Assessment; $<26$ of 30). ${ }^{22}$ Under the SPPB definition, a patient was classified as "frail" if his/her composite score was 9 or less after the following 3 functional assessments, each scored from 0 to 4 : a 5-m gait speed measurement, ${ }^{9}$ a side-byside, semi-tandem, and tandem stand balance tests, ${ }^{23}$ and the repeated chair stand test. ${ }^{23}$ Under the CFS definition, a patient was deemed "frail" if his/her given score, which is based on a clinical judgment regarding a patient's level of activity, comorbidities, and disabilities, was 4 or greater. ${ }^{19}$

All 7 constructs of the MFC were also analyzed individually as an indicator of frailty to determine whether any one in particular would be predictive of poor functional survival 1 year after cardiac surgery.

Health-related quality of life. The primary outcome variable was 1-year functional survival, defined as being alive at 1 year postsurgery and having a EuroQol-Visual Analogue Scale (EQ-VAS) score greater than 60. One-year postsurgery survival was determined by contacting the patient or patient's family. The EQ-VAS is a part of the EQ-5D questionnaire and is widely considered a validated tool used to measure HRQoL. ${ }^{24,25}$ The EQ-VAS instrument is a scale from 0 (worst imaginable health state) to 100 (best imaginable health state) with which patients record their self-rated health. We administered the EQ-5D questionnaire in person at a clinic follow-up or over the telephone 1 year after a patient's cardiac surgery. We chose an EQ-VAS less than 60 to represent poor HRQoL because it represented the median score for individuals with advanced heart failure, malignancy, and kidney failure, all of which are well-accepted states of poor HRQoL. ${ }^{26,27}$

Secondary outcomes. The secondary outcome variable was in-hospital morbidity/mortality, defined as death, stroke, prolonged ventilation (>24 hours), sternal infection, renal failure (dialysis), or return 
to the operating room. Hospital records were reviewed to collect data for this secondary outcome variable.

\section{Statistical Analysis}

Baseline characteristics between study patients and patients who were lost to follow-up were compared using the chi-square test or Fisher exact test for categoric variables and the $t$ test or Mann-Whitney test for continuous variables. To evaluate the internal validity of the Modified Fried criteria, SPPB, and CFS models, discrimination and reclassification were computed.

Discrimination, which is the ability of a model to separate patients who experience an outcome of interest into a different risk group from those who do not experience the outcome, was assessed using the area under the curve (AUC). We also included several composite outcome scores, including the Charlson comorbidity index and the Functional Comorbidity Index, which predict 1-year mortality and physical function, respectively.

To compare the improvement in discrimination of the frailty models relative to the euroSCORE II model, the Integrated Improvement Index $(\text { IDI })^{28}$ was calculated. Changes in reclassification with the addition of the frailty constructs were assessed using the category-free Net Reclassification Index (NRI) ${ }^{28}$ Category-free (continuous) NRI was chosen because of the lack of clinically accepted risk categories. The NRI describes the level of success with which a new model reclassifies a patient, that is, to a higher-risk group if he/she experienced the outcome of interest or to a lower-risk group if he/she did not experience the outcome. These statistics are being used more often in epidemiologic studies because of their higher sensitivity and intuitiveness in demonstrating predictive power than AUC statistics. ${ }^{9} P$ values for the IDI and NRI statistics were computed according to the methods described by Pencina and colleagues. ${ }^{29}$ One-year functional survival and in-hospital mortality/morbidity outcomes were analyzed separately. All analyses were performed using Statistical Analysis System version 9.3 (SAS Institute Inc, Cary, NC).

\section{RESULTS}

\section{Study Population}

A total of 235 consecutively consenting patients undergoing an elective or urgent cardiac surgery procedure were enrolled in this study (Figure 1). Forty-seven patients were subsequently excluded; 10 patients did not undergo cardiac surgery, 9 patients chose to discontinue study participation, and 28 patients were lost to follow-up (after 3 separate contact attempts) 1 year after cardiac surgery. As such, a sample size of 188 patients was available for the final analyses. Although all 188 patients completed a SPPB and CFS assessment, only 186 in the cohort completed the full MFC. Fifty-five (29.3\%) of the participants were women, and the median age was 71.0 years (interquartile range, 66.0-76.0) (Table 1). A total of 155 patients $(82.4 \%)$ underwent elective surgeries, and 33 patients $(17.6 \%)$ underwent urgent surgeries. The median euroSCORE II of the participants was 1.56 (interquartile range, 0.97-3.00).

\section{Factors Associated With Frailty}

Baseline frailty, defined using the Fried criteria, was associated with older age, a greater proportion of female patients, and a higher euroSCORE II when compared with the nonfrail cohort (Table 2). Postoperative hospital length of stay and incidence of delirium were higher among the frail cohort. The proportion of patients defined as being frail

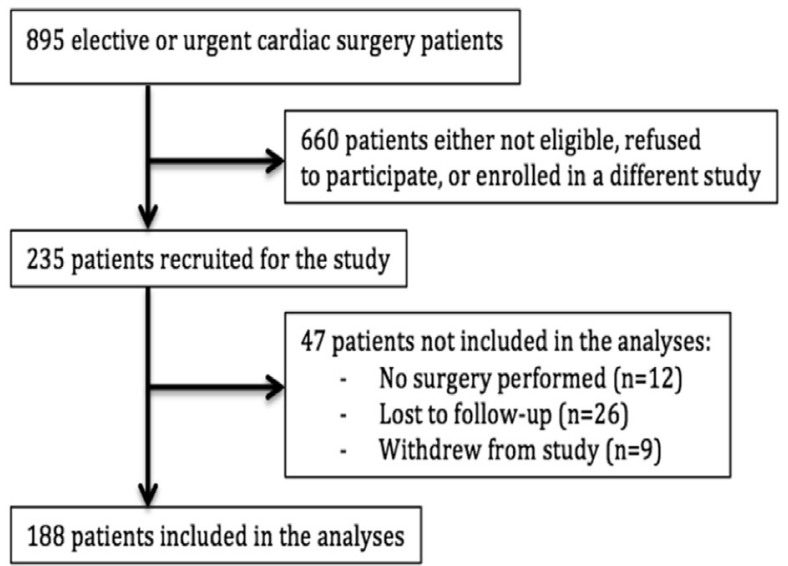

FIGURE 1. Flowchart of study cohort recruitment. Description of how patients undergoing cardiac surgery were recruited for our study and included in the analyses.

varied depending on the frailty scale used. The Modified Fried, SPPB, and CFS scales were $49.5 \%, 52.6 \%$, and $31.9 \%$, respectively (Figure 2).

\section{Association of Frailty With 1-Year Functional Survival}

The probability of functional survival in the entire cohort was $73.9 \%(n=139)$. After adjustment for the euroSCORE II, preoperative frailty was associated with a greater than 2- to approximately 3.5 -fold higher odds of poor functional survival, depending on which frailty definition was used (Table 3). The addition of any frailty assessment score consistently resulted in an improvement in the prognostic value of the euroSCORE II in classifying functional survival, as evidenced by an absolute improvement in the discrimination slope (IDI) and a category-free NRI. For the Modified Fried, SPPB, and CFS, there was an absolute improvement in the discrimination slope of $6.7 \%, 6.5 \%$, and $2.4 \%$ with a category-free classification improvement of $59.6 \%, 59.2 \%$, and $35.1 \%$, respectively (Table 4). There were no significant improvements in AUC with the addition of any frailty definition.

Individual Modified Fried frailty criteria of slow gait speed and cognitive impairment were associated with a similarly high rate of poor functional survival demonstrated by an adjusted odds ratio of 3.08 and 3.59, respectively (Table 5). Slow gait speed and cognitive impairment criteria also showed incremental value in identifying patients at risk of poor 1-year functional survival when compared with the euroSCORE II alone, as indicated by IDIs of $5.7 \%$ and $6.0 \%$, and NRIs of $51.6 \%$ and $57.7 \%$, respectively. The addition of individual Modified Fried frailty criteria did not significantly improve AUC values.

\section{Association of Frailty With Secondary Outcomes}

In this study, none of the frailty scales demonstrated that frailty results in a statistically significant improvement in 
TABLE 1. Preoperative patient characteristics compared between study patients and patients who did not complete study

\begin{tabular}{|c|c|c|c|c|}
\hline Preoperative variables & Study patients $(n=188)$ & $\begin{array}{c}\text { Patients who did not complete } \\
\text { study }(\mathrm{n}=37)\end{array}$ & $P$ value* & SD \\
\hline Age, $y$ & $71.0(66.0-76.0)$ & $70.0(67.0-76.0)$ & .75 & 0.06 \\
\hline Sex (female) & $55(29.3 \%)$ & $7(18.9 \%)$ & .20 & 0.24 \\
\hline BMI $\left(\mathrm{kg} / \mathrm{m}^{2}\right)$ & $28.4(25.2-32.1)$ & $27.8(25.9-32.8)$ & .91 & 0.01 \\
\hline Procedure & & & .75 & 0.20 \\
\hline CABG & $90(47.9 \%)$ & $16(43.2 \%)$ & & \\
\hline Valve & $56(29.8 \%)$ & $11(29.7 \%)$ & & \\
\hline $\mathrm{CABG}+$ valve & $33(17.6 \%)$ & $9(24.3 \%)$ & & \\
\hline Other & $9(4.8 \%)$ & $1(2.7 \%)$ & & \\
\hline Urgency & & & .33 & 0.17 \\
\hline Elective & $155(82.4 \%)$ & $28(75.7 \%)$ & & \\
\hline Urgent & $33(17.6 \%)$ & $9(24.3 \%)$ & & \\
\hline Current smoker & $9(4.8 \%)$ & $2(5.4 \%)$ & 1.00 & 0.17 \\
\hline Angina & $126(67.0 \%)$ & $25(67.6 \%)$ & .95 & -0.01 \\
\hline Previous MI & $64(34.0 \%)$ & $15(40.5 \%)$ & .45 & -0.13 \\
\hline Congestive heart failure & $101(53.7 \%)$ & $19(51.4 \%)$ & .74 & 0.06 \\
\hline Atrial fibrillation & $39(20.7 \%)$ & $12(32.4 \%)$ & .12 & -0.27 \\
\hline Cardiogenic shock & $3(1.6 \%)$ & $0(0.0 \%)$ & 1.00 & 0.18 \\
\hline Previous angioplasty/stent & $37(19.7 \%)$ & $4(10.8 \%)$ & .20 & 0.25 \\
\hline Previous cardiac surgery & $15(8.0 \%)$ & $2(5.4 \%)$ & .75 & 0.10 \\
\hline Diabetes & $60(31.9 \%)$ & $15(40.5 \%)$ & .31 & -0.18 \\
\hline Hypertension & $158(84.0 \%)$ & $33(89.2 \%)$ & .42 & -0.15 \\
\hline Dyslipidemia & $137(72.9 \%)$ & $29(78.4 \%)$ & .49 & -0.13 \\
\hline Peripheral vascular disease & $21(11.2 \%)$ & $7(18.9 \%)$ & .18 & -0.22 \\
\hline Cerebrovascular disease & $23(12.2 \%)$ & $8(21.6 \%)$ & .13 & -0.25 \\
\hline Chronic renal failure & $10(5.3 \%)$ & $1(2.7 \%)$ & .70 & 0.13 \\
\hline Pulmonary hypertension & $12(6.4 \%)$ & $2(5.4 \%)$ & 1.00 & 0.04 \\
\hline COPD & $23(12.5 \%)$ & $4(10.8 \%)$ & 1.00 & 0.05 \\
\hline Arthritis & $37(19.7 \%)$ & $3(8.1 \%)$ & .09 & 0.34 \\
\hline Visual impairment & $81(43.1 \%)$ & $11(29.7 \%)$ & .13 & 0.28 \\
\hline Hearing impairment & $16(8.5 \%)$ & $2(5.4 \%)$ & .74 & 0.12 \\
\hline Depression & $22(11.7 \%)$ & $4(10.8 \%)$ & 1.00 & 0.03 \\
\hline Falls in the past year & $10(5.3 \%)$ & $1(2.7 \%)$ & .70 & 0.13 \\
\hline Albumin $(\mathrm{g} / \mathrm{L})$ & $37.5(34.0-40.0)$ & $38.0(36.0-39.0)$ & .37 & -0.18 \\
\hline Creatinine $(\mu \mathrm{mol} / \mathrm{L})$ & $86.0(73.0-104.5)$ & $90.0(76.0-104.0)$ & .48 & 0.03 \\
\hline Creatinine clearance & $76.2(59.1-97.5)$ & $75.9(31.0-96.7)$ & .71 & -0.11 \\
\hline Hemoglobin $(\mathrm{g} / \mathrm{L})$ & $136.0(123.0-148.0)$ & $134.0(123.0-143.0)$ & .57 & 0.09 \\
\hline Hemoglobin A1C (\%) & $6.0(5.7-6.7)$ & $6.3(5.8-7.1)$ & .23 & 0.06 \\
\hline STS PROM $(\%)$ & $1.72(0.84-2.96)$ & $1.89(0.80-2.97)$ & .63 & 0.09 \\
\hline STS PROMM (\%) & $13.3(9.3-19.2)$ & $15.12(9.6-22.1)$ & .36 & -0.04 \\
\hline euroSCORE II (\%) & $1.56(0.97-3.00)$ & $2.28(1.50-3.31)$ & .13 & 0.08 \\
\hline Charlson Comorbidity Index & $2.0(1.0-3.0)$ & $2.0(1.0-3.0)$ & .56 & 0.11 \\
\hline Functional Comorbidity Index & $4.0(3.0-5.0)$ & $4.0(3.0-5.0)$ & .88 & 0.02 \\
\hline
\end{tabular}


TABLE 1. Continued

\begin{tabular}{lccr}
\hline \multicolumn{1}{c}{ Preoperative variables } & Study patients $(\mathbf{n}=\mathbf{1 8 8})$ & $\begin{array}{c}\text { Patients who did not complete } \\
\text { study }(\mathbf{n}=\mathbf{3 7})\end{array}$ & $\begin{array}{c}\boldsymbol{P} \text { value* } \\
\text { SD }\end{array}$ \\
\hline Modified Fried frail $($ score $\geq 3)$ & $92(49.5 \%)$ & $17(46.0 \%)$ & .70 \\
SPPB frail (SPPB $<10)$ & $97(51.6 \%)$ & $14(37.8 \%)$ & .07 \\
CFS $\geq 4$ & $60(31.9 \%)$ & $12(32.4 \%)$ & 0.28 \\
\hline
\end{tabular}

Continuous variables expressed as median (interquartile range) and categoric variables expressed as $\mathrm{N}$ (\%). $S D$, Standard deviation; $B M I$, body mass index; $C A B G$, coronary artery bypass grafting; $M I$, myocardial infarction; $C O P D$, chronic obstructive pulmonary disease; STS PROM, Society of Thoracic Surgeons Predicted Risk of Mortality; STS PROMM, Society of Thoracic Surgeons Predicted Risk of Mortality and Morbidity; euroSCORE II, European System for Cardiac Operative Risk Evaluation II; SPPB, Short Physical Performance Battery; $C F S$, Clinical Frailty Scale. *Continuous variables were compared using the Mann-Whitney test, and categoric variables were compared using the chi-square or Fisher exact test.

prediction of in-hospital morbidity/mortality when compared with the euroSCORE II alone. For the Modified Fried, SPPB, and CFS, there was an absolute improvement in the discrimination slope of $0.1 \%, 1.2 \%$, and $0.0 \%$ with a category-free classification improvement of $10.9 \%, 31.1 \%$, and $-3.0 \%$, respectively, all with $P$ values less than .05 (Table 4).

\section{DISCUSSION}

In this prospective cohort study of 188 adult patients undergoing cardiac surgery, the presence of preoperative frailty was associated with a 2- to 3.5-fold higher risk of poor functional survival 1 year after cardiac surgery. The addition of any comprehensive frailty assessment to the euroSCORE II resulted in a statistically significant improvement in the risk of poor 1-year functional survival when compared with the euroSCORE II alone. The magnitude of these improvements is consistent with well-known risk factors for morbidity and mortality in other prediction models, for example, cardiac markers such as troponin $\mathrm{T}$ improving the prediction of cardiovascular disease..$^{30-32}$ The Modified Fried and SPPB frailty definitions generated consistent prevalence rates of frailty in our population (ie, Modified Fried: 49.5\%, SPPB: 52.6\%) and provided incremental value in identifying individuals at risk of poor 1-year functional survival. Both the SPPB and the MFC were superior in improving the predictive ability of the euroSCORE II compared with the CFS. Of note, frailty prevalence rates in the present study (ie, $31.9 \%$ to $52.6 \%$ ) were similar to those in previous studies conducted in patients undergoing cardiac surgery; however, these rates remain significantly higher than the $14 \%$ of communitydwelling older adults who are considered frail. ${ }^{33}$ As expected, frail patients were older, were more likely to be female, and had an increased burden of comorbidities (ie, diabetes mellitus, cerebrovascular disease, chronic obstructive pulmonary disease, arthritis, peripheral vascular disease, and hypertension). With respect to postoperative outcomes, frail patients experienced longer intensive care unit length of stay and hospital length of stay and were more likely to experience postoperative delirium, which is consistent with previous literature. ${ }^{4,9}$
Many studies examining the influence of frailty on postoperative outcomes in patients undergoing cardiac surgery focus primarily on perioperative and in-hospital events. ${ }^{4,5,8,9}$ Although these outcomes are essential, understanding the risk factors of poor long-term functional outcomes after cardiac surgery is equally important. Likewise, previous studies linking frailty to long-term outcomes of cardiac surgery have primarily sought to understand its impact on mortality. ${ }^{8}$ These studies have consistently demonstrated that frailty assessments, defined using multiple criteria, are effective at predicting 1-year all-cause mortality. To our knowledge, this is the first study to examine the predictive ability of multiple frailty constructs in determining a composite of survival and HRQoL 1 year after cardiac surgery. Indeed, previous literature has confirmed that preoperative frailty status is associated with poor postoperative HRQoL in minimally invasive cardiac procedures; however, our study is the first to examine this association in patients undergoing major cardiac intervention. ${ }^{34}$

In undertaking the analysis of the 3 frailty assessment methods used in this study, the prevalence of frailty was similar between the MFC, which includes 3 domains of objective assessment (ie, physical ability, mood, and cognition), and the SPPB, which objectively assesses physical ability alone. According to the MFC and SPPB, a frail patient was approximately 3.5 times as likely to have a poor functional survival at 1 year compared with a nonfrail patient after adjustment for the euroSCORE II. The CFS is perhaps the most immediately "implementable" of these frailty evaluations and more semiquantitatively in nature provided incremental value in identifying patients at risk of poor 1-year outcomes, but at a lower degree when compared with the MFC and SPPB. However, the advantage of the CFS is that it is a more rapid tool requiring less training and resource allocation than the other frailty definitions used in this study. ${ }^{17}$ A more thorough and objective assessment of frailty (ie, the Modified Fried or the SPPB) appears to result in a greater proportion of patients defined as frail and has greater predictive capability of poor 1-year functional survival. This suggests that a more brief and subjective frailty assessment may not be comprehensive 
TABLE 2. Characteristics of "frail" versus "nonfrail" according to the modified Fried criteria

\begin{tabular}{|c|c|c|c|c|}
\hline Characteristic & Fried frail $(N=92)$ & Not Fried frail $(N=94)$ & $P$ value & SD \\
\hline \multicolumn{5}{|l|}{ Preoperative characteristics } \\
\hline Age, y & $73.0(67.0-79.5)$ & $70.0(66.0-73.0)$ & $<.01$ & 0.48 \\
\hline Sex (female) & $33(35.9 \%)$ & $21(22.3 \%)$ & .04 & 0.30 \\
\hline BMI $\left(\mathrm{kg} / \mathrm{m}^{2}\right)$ & $28.4(25.1-31.3)$ & $28.3(25.3-33.1)$ & .34 & -0.19 \\
\hline Diabetes mellitus & $36(39.1 \%)$ & $23(24.5 \%)$ & .03 & 0.32 \\
\hline Hemoglobin A1c (\%) & $6.1(5.8-7.1)$ & $6.0(5.7-6.5)$ & .27 & 0.22 \\
\hline Cerebrovascular disease & $17(18.5 \%)$ & $6(6.4 \%)$ & .01 & 0.37 \\
\hline COPD & $17(18.9 \%)$ & $6(6.5 \%)$ & .01 & 0.38 \\
\hline Clinical depression & $15(16.3 \%)$ & $7(7.5 \%)$ & .06 & 0.28 \\
\hline Arthritis & $25(27.2 \%)$ & $12(12.8 \%)$ & .01 & 0.37 \\
\hline Angina & $63(68.5 \%)$ & $61(64.9 \%)$ & .60 & 0.08 \\
\hline Smoking history & $56(61.5 \%)$ & $60(63.8 \%)$ & .75 & -0.05 \\
\hline Current smoker & $5(5.5 \%)$ & $4(4.3 \%)$ & .70 & 0.06 \\
\hline Albumin $(\mathrm{g} / \mathrm{L})$ & $37(34-39)$ & $38(35-40)$ & .03 & -0.23 \\
\hline Chronic renal failure & $8(8.7 \%)$ & $2(2.1 \%)$ & .06 & 0.29 \\
\hline Creatinine $(\mu \mathrm{mol} / \mathrm{L})$ & $86(70-116)$ & $86(76-99)$ & .90 & 0.25 \\
\hline Peripheral vascular disease & $15(16.3 \%)$ & $6(6.4 \%)$ & .03 & 0.32 \\
\hline Dyslipidemia & $68(73.9 \%)$ & $67(71.3 \%)$ & .69 & 0.06 \\
\hline Hypertension & $83(90.2 \%)$ & $73(77.7 \%)$ & .02 & 0.35 \\
\hline $\mathrm{CHF}$ & $53(58.2 \%)$ & $48(51.6 \%)$ & .37 & 0.13 \\
\hline MI & $34(37.0 \%)$ & $29(30.9 \%)$ & .38 & 0.13 \\
\hline Atrial fibrillation & $22(23.9 \%)$ & $16(17.0 \%)$ & .24 & 0.17 \\
\hline Previous angioplasty/stent & $23(25.0 \%)$ & $14(14.9 \%)$ & .08 & 0.25 \\
\hline Previous cardiac surgery & $6(6.5 \%)$ & $9(9.6 \%)$ & .44 & -0.11 \\
\hline euroSCORE II $(\%)$ & $2.06(1.26-3.71)$ & $1.30(0.85-2.03)$ & $<.01$ & 0.20 \\
\hline STS PROM (\%) & $1.85(1.08-3.55)$ & $1.30(0.75-2.23)$ & $<.01$ & 0.34 \\
\hline STS PROMM (\%) & $15.20(11.03-22.60)$ & $11.40(8.39-16.87)$ & $<.01$ & 0.43 \\
\hline \multicolumn{5}{|l|}{ Frailty characteristics } \\
\hline $\begin{array}{l}\text { Modified Fried Frailty } \\
\text { Score }\end{array}$ & $4(3-5)$ & $1(1-2)$ & $<.01$ & 3.10 \\
\hline Gait speed & $48(52.8 \%)$ & $8(8.5 \%)$ & $<.01$ & 1.09 \\
\hline Grip strength & $45(49.5 \%)$ & $5(5.4 \%)$ & $<.01$ & 1.14 \\
\hline Physical inactivity & $80(87.0 \%)$ & $36(38.3 \%)$ & $<.01$ & 1.16 \\
\hline Weight loss & $23(25.0 \%)$ & $5(5.3 \%)$ & $<.01$ & 0.57 \\
\hline Exhaustion & $60(65.2 \%)$ & $17(18.1 \%)$ & $<.01$ & 1.09 \\
\hline Cognitive impairment & $75(81.5 \%)$ & $35(37.6 \%)$ & $<.01$ & 1.00 \\
\hline Depression & $46(50.0 \%)$ & $5(5.3 \%)$ & $<.01$ & 1.15 \\
\hline \multicolumn{5}{|l|}{ Intraoperative characteristics } \\
\hline Procedure type & & & .79 & 0.15 \\
\hline Isolated CABG & $47(51.1 \%)$ & $41(43.6 \%)$ & & \\
\hline Isolated valve & $26(28.3 \%)$ & $30(31.9 \%)$ & & \\
\hline $\mathrm{CABG}+$ valve & $15(16.3 \%)$ & $18(19.2 \%)$ & & \\
\hline Other & $4(4.4 \%)$ & $5(5.3 \%)$ & & \\
\hline CPB time & $92(73-122)$ & $97(79-138)$ & .28 & -0.14 \\
\hline \multicolumn{5}{|l|}{ Postoperative outcomes } \\
\hline ICU LOS (d) & $2(1-4)$ & $1(1-2)$ & .05 & -0.03 \\
\hline Hospital LOS (d) & $9(6-14)$ & $6(5-11)$ & $<.01$ & 0.22 \\
\hline ICU LOS $>72 \mathrm{~h}$ & $33(36.3 \%)$ & $23(24.5 \%)$ & .08 & 0.26 \\
\hline Hospital LOS $>7 \mathrm{~d}$ & $65(71.4 \%)$ & $42(44.7 \%)$ & $<.01$ & 0.56 \\
\hline Major adverse event (30 d) & $4(4.4 \%)$ & $1(1.1 \%)$ & .21 & 0.13 \\
\hline Postoperative delirium & $30(33.0 \%)$ & $14(14.5 \%)$ & $<.01$ & 0.43 \\
\hline In-hospital mortality & $3(3.3 \%)$ & $1(1.1 \%)$ & .37 & 0.15 \\
\hline \multicolumn{5}{|l|}{ 1-y follow-up outcomes } \\
\hline EuroQol-VAS score & $74(50-83)$ & $80(70-87)$ & $<.01$ & -0.54 \\
\hline
\end{tabular}


TABLE 2. Continued

\begin{tabular}{lcrr}
\hline \multicolumn{1}{c}{ Characteristic } & Fried frail $(\mathbf{N}=\mathbf{9 2})$ & Not Fried frail $(\mathbf{N}=\mathbf{9 4})$ & $\boldsymbol{P}$ value \\
\hline EuroQol-VAS $\leq 60$ & $26(28.3 \%)$ & $9(9.6 \%)$ & $<.01$ \\
1-y mortality & $9(9.8 \%)$ & $5(5.3 \%)$ & .25 \\
1-y poor functional & $35(38.0 \%)$ & $14(14.9 \%)$ & 0.55 \\
\hline
\end{tabular}

Continuous variables are expressed as median (interquartile range), and categoric variables are expressed as N (\%). Continuous variables were compared using the MannWhitney test, and categoric variables were compared using the chi square or Fisher exact test. $S D$, Standard deviation; $B M I$, body mass index; $C O P D$, chronic obstructive pulmonary disease; $C H F$, congestive heart failure; MI, myocardial infarction; euroSCORE II, European System for Cardiac Operative Risk Evaluation II; STS PROM, Society of Thoracic Surgeons Predicted Risk of Mortality; STS PROMM, Society of Thoracic Surgeons Predicted Risk of Mortality and Morbidity; CABG, coronary artery bypass graft; $C P B$, cardiopulmonary bypass; $I C U$, intensive care unit; $L O S$, length of stay; VAS, Visual Analogue Scale.

enough to discover all patients who are at increased risk, and thus may not adequately estimate level of risk.

In our analysis, we further sought to determine which specific components within the MFC were most strongly associated with poor functional survival 1 year after cardiac surgery. Previous literature from Afilalo and colleagues ${ }^{5,9}$ has demonstrated a strong association between slow gait speed and an increased risk of in-hospital morbidity and mortality after cardiac surgery. In the present study, slow gait speed and cognitive impairment were associated with a similarly strong association poor functional survival at 1 year as the MFC and SPPB. These specific criteria may represent frailty assessment tools that are less resource intensive to implement when compared with the more thorough testing required for the definitions based on MFC and SPPB.

\section{Clinical Importance}

We propose that identifying patients at risk for poor functional survival would allow clinicians to improve the quality of patients' informed consent. ${ }^{15}$ Recognizing this vulnerable cohort of patients also allows the healthcare team to target modifiable risk factors in this vulnerable group both preoperatively and postoperatively. Specifically, previous investigators have proposed physical frailty to be highly

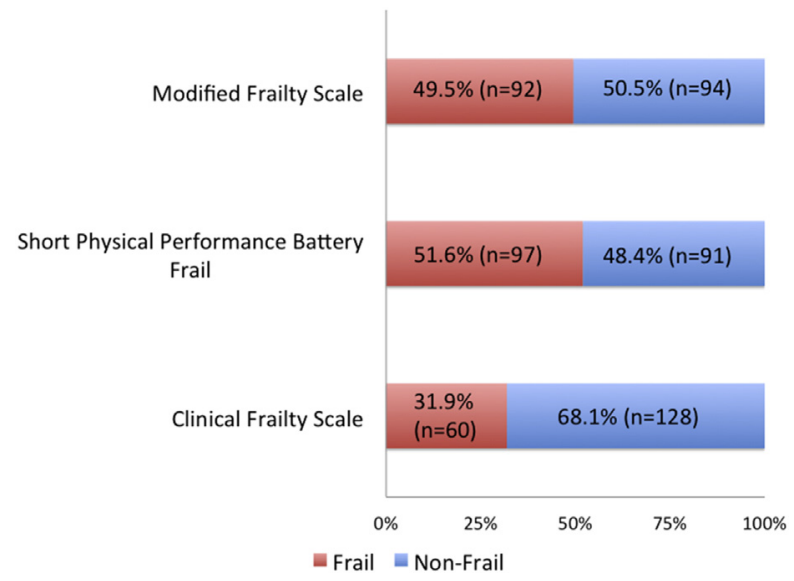

FIGURE 2. The prevalence of frailty. Depiction of the proportions of patients undergoing cardiac surgery deemed frail preoperatively using 3 different frailty definitions. related to sarcopenia or the loss of muscle tissue due to aging. ${ }^{35,36}$ A recent systematic review has demonstrated that exercise interventions, especially resistance training, may have a role in reversing sarcopenia in older adults, and thus possibly reversing frailty. ${ }^{37}$ Therefore, one could envision that if a reduction in frailty in the preoperative and postoperative setting patient was possible, improvements in functional survival 1 year after cardiac surgery may be achievable. ${ }^{38}$

The significant time and resources allocated to conducting comprehensive frailty assessments in routine clinical practice must be taken into consideration. For example, it may not be practical for physicians and other health care providers to complete a Modified Fried assessment (ie, 15-25 minutes) in every patient. On the basis of the data presented in the present study, the SPPB (ie, 510 minutes to complete) is shorter and as effective in predicting functional survival postoperatively when compared with the MFC. Even so, the SPPB may be impractical to implement in clinical settings. The CFS was developed to be a quick and subjective tool for assessing frailty; however, the data from this study would suggest it might lack sensitivity to predict an increased risk of poor functional survival in patients undergoing cardiac surgery. Our study also demonstrated that the 5-m gait speed assessment might be just as effective as the MFC and SPPB composite scores, while taking approximately 1 minute to administer. Although the 5-m gait speed assessment is an important indicator of sarcopenia, at this time, it is difficult to recommend the utility of using one test over another to stratify risk among surgical patients.

\section{Study Limitations}

There are several important limitations when interpreting the results of our study. First, the majority of patients enrolled in this study were undergoing elective procedures (ie, $82.4 \%$ ). As such, this may limit the generalizability of the study findings in patients requiring an urgent or emergency cardiac procedure. However, it is unlikely that a frail older adult patient undergoing a more urgent procedure would have superior 1-year functional survival than a patient requiring an elective procedure. Second, several patients who were screened refused to participate in the study. Therefore, it is likely to be an element of selection 
TABLE 3. Association between preoperative frailty and 1-year poor functional survival

\begin{tabular}{lccccc}
\hline \multicolumn{1}{c}{ Frailty definition } & Frail & Not frail & $\boldsymbol{P}$ value & Unadjusted OR (95\% CI) & Adjusted OR (95\% CI)* \\
\hline $\begin{array}{l}\text { Modified Fried frail (score } \\
\geq 3 \text { ) }\end{array}$ & $38.0 \%(35)$ & $14.9 \%(14)$ & $<.01$ & $3.51(1.73-7.11)$ & $3.44(1.69-7.00)$ \\
SPPB frail (SPPB $\leq 9)$ & $37.1 \%(36)$ & $14.3 \%(13)$ & $<.01$ & $3.54(1.73-7.25)$ & $3.47(1.69-7.12)$ \\
CFS frail (CFS $\geq 4)$ & $36.7 \%(22)$ & $21.1 \%(27)$ & .02 & $2.17(1.10-4.25)$ & $2.08(1.05-4.12)$ \\
\hline
\end{tabular}

$O R$, Odds ratio; $C I$, confidence interval; SPPB, Short Physical Performance Battery; $C F S$, Clinical Frailty Scale. *Adjusted for the euroSCORE II. Categoric variables expressed as $\%(\mathrm{~N})$.

bias, wherein robust patients were more agreeable to enroll in the study. We speculate that patients with more severe frailty may have been less likely to enroll in the study because of the time commitment required for baseline and follow-up testing. Thus, the study population may not accurately represent a true elective patient population, which would include both robust and severely frail patients. In future studies, we are seeking to develop and implement a more concise assessment methodology to identify an appropriate level of information required for risk prediction, while not being a burden to the patient. Third, this study lost $20 \%$ of patients to follow-up. We speculate that participants became unable to communicate with the research team because of changes in telephone number, changes in residence, or worsening health condition. Furthermore, because of the unique geographic context of the study site, it is possible that travel from remote rural locations of the province presented a barrier to participating in the follow-up protocol for some study participants. Even so, the percentage of patients lost to follow-up is similar to other studies in cardiac surgery, with some studies losing greater than $45 \%$ of patients to follow up. ${ }^{10}$ We also aimed to conduct follow-up assessments within 2 to 3 months of the desired 1-year follow-up period; however, because of patient availability and scheduling, follow-up assessments ranged from 9 to 19 months after cardiac surgery. We acknowledge that there may be differences in outcomes, specifically with respect to HRQoL due to the range of follow-up appointments. However, the majority $(52 \%)$ of the appointments were scheduled within 3 months of the target 1-year follow-up date. We also acknowledge that poor HRQoL at 1 year may reflect impaired HRQoL at baseline before surgical intervention. However, the EQVAS was not administered during the preoperative period. In future studies, we endeavor to investigate changes in HRQoL throughout the perioperative period.

Frailty has been associated with several short-term outcomes after cardiac surgery, including postoperative major morbidity, mortality, adverse cardiac and cerebrovascular events, secondary in-hospital outcomes, and postoperative delirium. ${ }^{4,5,8-11}$ This present study did not show statistical significance of frailty improving prediction of in-hospital mortality/morbidity when compared with the euroSCORE II alone. A reason for this lack of significance may have been due to our cohort population consisting of mostly $(82.4 \%)$ elective procedures, which generally have more favorable outcomes than urgent and emergency procedures. Another possible reason for this lack of significance could have been our relatively small sample size, which in turn had a small incidence of in-hospital mortality. As such, our analysis was not powered to include a large number of covariates in the multivariable models; therefore, we decided to include the euroSCORE II because it provides a clinically validated surgical risk score that includes a large number of covariates. The low postoperative mortality rate at this study's cardiac surgery center relative to reported outcomes from other Canadian cardiac surgery centers may at least partially explain the lack of incremental value

TABLE 4. Improvements in prediction of 1-year functional survival and in-hospital mortality/morbidity by the addition of frailty* (compared with European System for Cardiac Operative Risk Evaluation II)

\begin{tabular}{|c|c|c|c|c|c|c|c|}
\hline Outcome & Frailty definition & Improvement in C-statistic & $P$ value & IDI & $P$ value & NRI & $P$ value \\
\hline \multirow[t]{3}{*}{$\begin{array}{l}\text { In-hospital mortality/ } \\
\text { morbidity* }\end{array}$} & $\begin{array}{l}\text { Modified Fried frail (score } \\
\geq 3 \text { ) }\end{array}$ & -0.039 & .23 & $0.1 \%$ & .68 & $10.9 \%$ & .59 \\
\hline & SPPB frail $(\mathrm{SPPB} \leq 9)$ & -0.02 & .57 & $1.2 \%$ & .15 & $31.1 \%$ & .13 \\
\hline & CFS frail $(\mathrm{CFS} \geq 4)$ & 0.015 & .14 & $0.0 \%$ & .84 & $-3.0 \%$ & .88 \\
\hline \multirow[t]{3}{*}{ 1-y functional survival $\dagger$} & $\begin{array}{l}\text { Modified Fried frail (score } \\
\geq 3 \text { ) }\end{array}$ & 0.041 & .18 & $6.7 \%$ & $<.01$ & $59.6 \%$ & $<.01$ \\
\hline & SPPB frail $(\mathrm{SPPB} \leq 9)$ & 0.032 & .30 & $6.5 \%$ & $<.01$ & $59.2 \%$ & $<.01$ \\
\hline & CFS frail $(\geq 4)$ & -0.014 & .57 & $2.4 \$$ & .04 & $35.1 \%$ & .03 \\
\hline
\end{tabular}

IDI, Integrated Improvement Index; NRI, Net Reclassification Index; SPPB, Short Physical Performance Battery; CFS, Clinical Frailty Scale. *In-hospital morbidity/mortality defined as death, stroke, prolonged ventilation ( $>24 \mathrm{~h}$ ), sternal infection, renal failure (dialysis), or return to the operating room. $\dagger$ One-year functional survival defined as being alive at 1 year or having EuroQol-VAS score greater than 60 . 
TABLE 5. Association between preoperative modified Fried criteria and 1-year poor functional survival

\begin{tabular}{|c|c|c|c|c|c|c|c|c|c|c|c|}
\hline Frailty definition & Frail & Nonfrail & $\begin{array}{c}P \\
\text { value }\end{array}$ & $\begin{array}{c}\text { Unadjusted } \\
\text { OR }(95 \% \text { CI })\end{array}$ & $\begin{array}{c}\text { Adjusted } \\
\text { OR }(95 \% \mathbf{C I})^{*}\end{array}$ & C-Statistic & $\begin{array}{c}P \\
\text { value }\end{array}$ & IDI & $\begin{array}{c}P \\
\text { value }\end{array}$ & $\mathbf{N R I}+$ & $\begin{array}{c}P \\
\text { value }\end{array}$ \\
\hline $\begin{array}{l}\text { Modified Fried } \\
\quad \text { Frail }(\text { score } \geq 3)\end{array}$ & $38.0 \%(35)$ & $14.9 \%(14)$ & $<.01$ & $3.51(1.73-7.11)$ & $3.44(1.69-7.00)$ & 0.712 & .18 & $6.7 \%$ & $<.01$ & $59.6 \%$ & $<.01$ \\
\hline Gait speed & $42.9 \%(24)$ & $19.1 \%(25)$ & $<.01$ & $3.18(1.60-6.31)$ & $3.08(1.54-6.18)$ & 0.692 & .43 & $5.7 \%$ & $<.01$ & $51.6 \%$ & $<.01$ \\
\hline Grip strength & $40.0 \%(20)$ & $21.3 \%(29)$ & .01 & $2.46(1.22-4.95)$ & $2.40(1.19-4.84)$ & 0.672 & .98 & $3.3 \%$ & .02 & $37.8 \%$ & .02 \\
\hline Physical inactivity & $29.1 \%(34)$ & $21.1 \%(15)$ & .23 & $1.53(0.76-3.07)$ & $1.53(0.76-3.07)$ & 0.642 & .44 & $0.8 \%$ & .20 & $19.4 \%$ & .24 \\
\hline Weight loss & $39.3 \%(11)$ & $23.8 \%(38)$ & .08 & $2.08(0.90-4.82)$ & $2.06(0.89-4.79)$ & 0.668 & .90 & $1.6 \%$ & .13 & $20.4 \%$ & .22 \\
\hline Exhaustion & $35.1 \%(27)$ & $18.9 \%(21)$ & .02 & $2.18(1.13-4.23)$ & $2.14(1.10-4.16)$ & 0.674 & .94 & $2.7 \%$ & .03 & $38.3 \%$ & .02 \\
\hline $\begin{array}{l}\text { Cognitive } \\
\text { impairment }\end{array}$ & $35.5 \%(39)$ & $13.0 \%(10)$ & $<.01$ & $3.68(1.70-7.95)$ & $3.59(1.65-7.78)$ & 0.717 & .22 & $6.0 \%$ & $<.01$ & $57.7 \%$ & $<.01$ \\
\hline Depression & $35.3 \%(18)$ & $22.6 \%(31)$ & .08 & $1.86(0.93-3.76)$ & $1.82(0.90-3.67)$ & 0.651 & .56 & $1.5 \%$ & .11 & $26.0 \%$ & .12 \\
\hline
\end{tabular}

Categoric variables expressed as \% (N). OR, Odds ratio; $C I$, confidence interval; IDI, Integrated Improvement Index; NRI, Net Reclassification Index. $*$ Adjusted for the euroSCORE II. †Improvement in prediction of 1-year poor functional survival compared with the euroSCORE II alone.

for in-hospital outcomes. (Canadian Institute for Health Information 2011-2014 data not shown). In our initial analysis, we demonstrated a $1.1 \%$ operative mortality rate in the nonfrail cohort and a $3.3 \%$ operative mortality rate in the frail cohort. If this trend continued, a sample size of 690 patients in each group would be required to detect these differences with a 2-tailed alpha of 0.05 and a power of $80 \%$. Although a standard definition of functional survival does not currently exist in the literature, we chose the EQ-VAS cutoff score of 60 as a measure of adequate HRQoL and to identify a relevant patient-centered health outcome.

\section{Future Directions}

This study needs to be replicated in other centers to determine whether the frailty measurement tools, along with their individual criteria, show similar ability to predict long-term functional survival as was shown in this study. Investigation into which frailty assessment is most effective at improving this prediction needs to occur and investigation into which is the most practical in terms of cost, time, and resources required to implement. Our research team is currently investigating the role of preoperative exercise interventions in frail patients undergoing cardiac surgery with the hypothesis that improving domains of frailty ("prehabilitation") will correlate with improvements in mortality and functional survival. ${ }^{38}$

\section{CONCLUSIONS}

Preoperative frailty was associated with poor functional survival 1 year after cardiac surgery. The addition of any quantitative or semiquantitative frailty measure to the euroSCORE II provided incremental value in identifying patients at risk of poor 1-year functional survival. Future research should investigate the feasibility of incorporating frailty assessment tools to assist with patient selection, promote shared-decision making, and identify potentially vulnerable patients requiring perioperative risk optimization.

\section{Conflict of Interest Statement}

R.C.A. has received funding in the way of an unrestricted educational grant from Pfizer Canada Inc, for work not related to the data presented in this article. All other authors have nothing to disclose with regard to commercial support.

\section{References}

1. Rosamond W, Flegal K, Furie K, Go A, Greenlund K, Haase N, et al. Heart disease and stroke statistics-2008 Update: a report from the American Heart Association Statistics Committee and Stroke Statistics Subcommittee. Circulation. 2008;117:e25-146.

2. Rumsfeld JS. Valve surgery in the elderly: a question of quality (of life)? J Am Coll Cardiol. 2003;42:1215-7.

3. Tsevat J, Dawson NV, Wu AW, Lynn J, Soukup JR, Cook EF, et al. Health values of hospitalized patients 80 years or older. J Am Med Assoc. 1998;279: $371-5$.

4. Jung P, Pereira MA, Hiebert B, Song X, Rockwood K, Tangri N, et al. The impact of frailty on postoperative delirium in cardiac surgery patients. J Thorac Cardiovasc Surg. 2015;149:869-75. e1-2.

5. Afilalo J, Mottillo S, Eisenberg MJ, Alexander KP, Noiseux N, Perrault LP, et al. Addition of frailty and disability to cardiac surgery risk scores identifies elderly patients at high risk of mortality or major morbidity. Circ Cardiovasc Qual Outcomes. 2012;5:222-8.

6. Fried LP, Tangen CM, Walston J, Newman AB, Hirsch C, Gottdiener J, et al. Frailty in older adults: evidence for a phenotype. J Gerontol A Biol Sci Med Sci. 2001;56:M146-56.

7. Song X, Mitnitski A, Rockwood K. Prevalence and 10-year outcomes of frailty in older adults in relation to deficit accumulation. J Am Geriatr Soc. 2010;58: 681-7.

8. Sepehri A, Beggs T, Hassan A, Rigatto C, Shaw-Daigle C, Tangri N, et al. The impact of frailty on outcomes after cardiac surgery: a systematic review. J Thorac Cardiovasc Surg. 2014;148:3110-7.

9. Afilalo J, Eisenberg MJ, Morin J-F, Bergman H, Monette J, Noiseux N, et al. Gait speed as an incremental predictor of mortality and major morbidity in elderly patients undergoing cardiac surgery. J Am Coll Cardiol. 2010;56: 1668-76.

10. Sündermann S, Dademasch A, Rastan A, Praetorius J, Rodriguez H, Walther T, et al. One-year follow-up of patients undergoing elective cardiac surgery assessed with the Comprehensive Assessment of Frailty test and its simplified form. Interact Cardiovasc Thorac Surg. 2011;13:119-23.

11. Chen MA. Frailty and cardiovascular disease: potential role of gait speed in surgical risk stratification in older adults. J Geriatr Cardiol. 2015;12:44-56. 
12. Puskas JD, Kilgo PD, Thourani VH, Lattouf OM, Chen E, Vega JD, et al. The Society of Thoracic Surgeons 30-day predicted risk of mortality score also predicts long-term survival. Ann Thorac Surg. 2012;93:26-35.

13. Barili F, Pacini D, Capo A, Rasovic O, Grossi C, Alamanni F, et al. Does euroSCORE II perform better than its original versions? A multicentre validation study. Eur Heart J. 2013;34:22-9.

14. Manji RA, Arora RC, Singal RK, Hiebert B, Moon MC, Freed DH, et al. Longterm outcome and predictors of noninstitutionalized survival subsequent to prolonged intensive care unit stay after cardiac surgical procedures. Ann Thorac Surg. 2016;101:56-63.

15. Abah U, Dunne M, Cook A, Hoole S, Brayne C, Vale L, et al. Does quality of life improve in octogenarians following cardiac surgery? A systematic review. BMJ Open. 2015;5:e006904.

16. da Câmara SMA, Alvarado BE, Guralnik JM, Guerra RO, Maciel ÁCC. Using the Short Physical Performance Battery to screen for frailty in young-old adults with distinct socioeconomic conditions. Geriatr Gerontol Int. 2013;13:421-8.

17. Rockwood K, Song X, Macknight C, Bergman H, Hogan DB, Mcdowell I, et al. A global clinical measure of fitness and frailty in elderly people. CMAJ. 2005; 173:489-95.

18. Radloff LS. The CES-D Scale: a self-report depression scale for research in the general population. Appl Psychol Meas. 1977;1:385-401.

19. Hoyl MT, Alessi CA, Harker JO, Josephson KR, Pietruszka FM, Koelfgen M, et al. Development and testing of a five-item version of the Geriatric Depression Scale. J Am Geriatr Soc. 1999;47:873-8.

20. Rinaldi P, Mecocci P, Benedetti C, Ercolani S, Bregnocchi M, Menculini G, et al. Validation of the five-item geriatric depression scale in elderly subjects in three different settings. J Am Geriatr Soc. 2003;51:694-8.

21. Paffenbarger RS, Blair SN, Lee IM, Hyde RT. Measurement of physical activity to assess health effects in free-living populations. Med Sci Sports Exerc. 1993;25: 60-70.

22. Nasreddine ZS, Phillips NA, Bédirian V, Charbonneau S, Whitehead V, Collin I, et al. The Montreal Cognitive Assessment, MoCA: a brief screening tool for mild cognitive impairment. J Am Geriatr Soc. 2005;53:695-9.

23. Guralnik JM, Ferrucci L, Simonsick EM, Salive ME, Wallace RB. Lower-extremity function in persons over the age of 70 years as a predictor of subsequent disability. N Engl J Med. 1995;332:556-61.

24. Brooks R. EuroQol: the current state of play. Health Policy (New York). 1996;37: 53-72.

25. Van Laar C, Kievit PC, Noyez L. Surgical aortic valve replacement in patients older than 75 years: is there really a quality of life benefit? Netherlands Hear J. 2015;23:174-9.
26. Calvert MJ, Freemantle N, Cleland JGF. The impact of chronic heart failure on health-related quality of life data acquired in the baseline phase of the CAREHF study. Eur J Heart Fail. 2005;7:243-51.

27. Møller AH, Erntoft S, Vinding GR, Jemec GBE. A systematic literature review to compare quality of life in psoriasis with other chronic diseases using EQ-5D-derived utility values. Patient Relat Outcome Meas. 2015;6: $167-77$

28. Rigatto C, Sood MM, Tangri N. Risk prediction in chronic kidney disease: pitfalls and caveats. Curr Opin Nephrol Hypertens. 2012;21:612-8.

29. Pencina MJ, D'Agostino RB, D'Agostino RB, Vasan RS. Evaluating the added predictive ability of a new marker: from area under the ROC curve to reclassification and beyond. Stat Med. 2008;27:157-72.

30. Matsushita K, Sang Y, Ballew SH, Astor BC, Hoogeveen RC, Solomon SD, et al. Cardiac and kidney markers for cardiovascular prediction in individuals with chronic kidney disease: the Atherosclerosis Risk in Communities Study. Arterioscler Thromb Vasc Biol. 2014;34:1770-7.

31. Duschek N, Stojakovic T, Ghai S, Strassegger J, Basic J, Scharnagl H, et al. Ratio of apolipoprotein A-II/B improves risk prediction of postoperative survival after carotid endarterectomy. Stroke. 2015;46:1700-3.

32. Molshatzki N, Drory Y, Myers V, Goldbourt U. Role of socioeconomic status measures in long-term mortality risk prediction after myocardial infarction. Med Care. 2011;49:673-8.

33. Shamliyan T, Talley KMC, Ramakrishnan R, Kane RL. Association of frailty with survival: a systematic literature review. Ageing Res Rev. 2013;12 719-36.

34. Kim DH, Kim CA, Placide S, Lipsitz LA, Marcantonio ER. Preoperative frailty assessment and outcomes at 6 months or later in older adults undergoing cardiac surgical procedures. Ann Intern Med. 2016;165:650.

35. Cesari M, Landi F, Vellas B, Bernabei R, Marzetti E. Sarcopenia and physical frailty: two sides of the same coin. Front Aging Neurosci. 2014;6:1-4.

36. Michel J-P, Cruz-Jentoft AJ, Cederholm T. Frailty, exercise and nutrition. Clin Geriatr Med. 2015;31:375-87.

37. Borst SE. Interventions for sarcopenia and muscle weakness in older people. Age Ageing. 2004;33:548-55.

38. Stammers AN, Kehler DS, Afilalo J, Avery LJ, Bagshaw SM, Grocott HP, et al Protocol for the PREHAB study-Pre-operative Rehabilitation for reduction of Hospitalization After coronary Bypass and valvular surgery: a randomised controlled trial. BMJ Open. 2015;5:e007250.

Key Words: frailty, cardiac surgery, long-term outcomes, survival, HRQoL

Readers who found these articles interesting may also like to read the following papers found in recent and future issues of our sister publications, Seminars in Thoracic and Cardiovascular Surgery and Operative Techniques in Thoracic and Cardiovascular Surgery!

\section{Acquired: Perioperative Management}

ORIGINAL SUBMISSION: Early Outcomes with Rapid-Deployment Versus Stented Biological Valves: a Propensity-Match Analysis Anthony Nguyen. Semin Thoracic Surg 2017: In press.

ORIGINAL SUBMISSION: Randomized Trial of Carnitine for the Prevention of Perioperative Atrial Fibrillation Farzaneh Dastan. Semin Thoracic Surg 2017: In press.

ORIGINAL SUBMISSION: Carbon Dioxide Insufflation during Cardiac Surgery. Meta-Analysis of Randomized Controlled Trials Umberto Benedetto. Semin Thoracic Surg 2017: In press.

ORIGINAL SUBMISSION: The Effects of Steroids on Coagulation Dysfunction Induced by Cardiopulmonary Bypass: A Steroids in Cardiac Surgery (SIRS) Trial Substudy Domenico Paparella. Semin Thoracic Surg 2017: 35-44

Editorial Commentary: Steroids and Cardiopulmonary Bypass: a Never-ending Story Thierry Carrel. Semin Thoracic Surg 2017: $45-46$. 